6 Karim ME, Shaikh S. Newly enacted mental health law in Bangladesh. BJPsych Int [Epub ahead of print] 1 Feb 2021: Available from: https://doi.org/10.1192/bji.2021.1

7 Department of Prisons, Bangladesh. Prison Population Statistics, 2017. Department of Prisons, 2017 (https://prison.com.bd/ prisonsite/assets/userfiles/files/Prison\%20Statistes\%202\%20.pdf).

8 Baranyi G, Scholl C, Fazel S, Patel V, Priebe S, Mundt AP. Severe mental illness and substance use disorders in prisoners in low-income and middle-income countries: a systematic review and meta-analysis of prevalence studies.Lancet Global Health 2019; 7: e461-71.

9 Fazel S, Seewald K. Severe mental illness in 33588 prisoners worldwide: systematic review and meta-regression analysis. $\mathrm{Br}]$ Psychiatry 2012; 200: 364-73.
10 Fazel S, Hayes AJ, Bartellas K, Clerici M, Trestman R. Mental health of prisoners: prevalence, adverse outcomes, and interventions. Lancet Psychiatry 2016; 3: 871-81.

11 Fu Z, Burger H, Arjadi R, Bockting CLH. Effectiveness of digital psychological interventions for mental health problems in low-income and middle-income countries: a systematic review and meta-analysis. Lancet Psychiatry 2020; 7: 851-64.

12 Forrester A, Piper M. The WPA's prison health position statement and curriculum. World Psychiatry 2020; 19(1): 125.

United Nations Office on Drugs and Crime. The United Nations Standard Minimum Rules for the Treatment of Prisoners (The Nelson Mandela Rules). United Nations, 2015.

SPECIAL PAPER

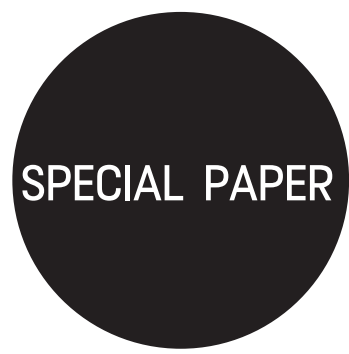

\title{
Stressors and mental health in Bangladesh: current situation and future hopes*
}

\author{
Faruq Alam, ${ }^{1}$ Rubina Hossain, ${ }^{1}$ Helal Uddin Ahmed, ${ }^{1}$ \\ Mohammad Tariqul Alam, ${ }^{1}$ Mekhala Sarkar ${ }^{1}$ and Uriel Halbreich ${ }^{2}$
}

National Institute of Mental Health, Dhaka, Bangladesh

${ }^{2}$ School of Medicine and BioMedical Sciences, State University of New York At Buffalo, USA. Email: uhalbreich@gmail.com

Keywords. Adjustment disorders; post-traumatic stress disorder; trauma; transcultural psychiatry; stress.

First received 15 May 2020 Final revision 24 Sep 2020

Accepted 7 Oct 2020

doi:10.1192/bji.2020.57

(c) The Authors 2020. This is an Open Access article, distributed under the terms of the Creative Commons Attribution-

NonCommercial-NoDerivatives org/licenses/by-nc-nd/4.0/), which permits non-commercial re-use distribution, and reproduction in any medium, provided the original work is unaltered and is properly cited. The written permission of Cambridge Univers or commercial re-use or in order to cre ate a derivative work.

*A podcast for this article is available at: https://soundcloud. com/bjpsych/bji-2020-57
Bangladesh is a densely populated emerging country in South Asia. Since its harsh independence war, it has suffered from repeated floods and other natural and maninflicted disasters. Internal migration from rural areas to the urban centres has increased crowdedness, pollution and social conflicts. Furthermore, in recent years, the country has absorbed close to a million refugees from Myanmar. These stressors have been associated with an increase in mental disorders and symptoms with which the country is struggling. Lack of resources and a shortage of human capital have weakened the national capacity to efficiently respond to situational stressors or disasters. For assessment of stress-related mental health issues, information available from the Ministry of Health and the National Institute of Mental Health was collected and supplemented by external reports. It is promising that the government's approach of responding to mental health needs only after the occurrence of a crisis has recently been replaced by the concept of total management through primary healthcare. There is a need for development of adequate infrastructure, logistics and workforce support, as well as establishment of multidisciplinary teams of management and clinical services. Collaboration of all related sectors of the government and an overall increase in government funding for mental health are essential.

\section{Background}

Bangladesh is a developing nation in South-East Asia that became a separate political and economic entity only 50 years ago. It was a part of the British Raj and then pre-Independence India until 1947, when it became an eastern province of Pakistan. Following its 'Great Liberation War' in 1971, the country became independent and was named Bangladesh. ${ }^{1}$ Covering 147570 square kilometres on the Bay of Bengal, it borders India and Myanmar. The population of Bangladesh is roughly 163 million. The country has one of the highest population densities in the world, at 1102 people per square kilometre: $89 \%$ are Muslims, $10 \%$ are Hindu and $1 \%$ others; $38.2 \%$ of the population is urban; and migration from rural areas to urban centres is substantial and causes congestion and rapid construction. In the capital, Dhaka, the population is 21 million people and growing. ${ }^{2}$ The GDP per capita is $\$ 4200$, which indicates that Bangladesh is a lower middle-income economy. ${ }^{3}$ Life expectancy is 74.2 years (133rd in the world), the maternal mortality rate is 173 per 100000 live births and infant mortality is 28.3 per 1000 live births. ${ }^{2}$

There are only 0.53 physicians and 0.8 hospital beds per 1000 population. In rural districts, 'village doctors' with no formal training provide $65 \%$ of healthcare.

Modern mental healthcare in Bangladesh is deficient owing to limited human and financial resources. Only 220 psychiatrists and about 50 trained clinical psychologists serve the whole nation. ${ }^{1}$ According to the World Health 
Organization (WHO) Assessment Instrument for Mental Health Systems, in 2007 the total number of workers in mental health facilities was 0.49 per 100000 population, among which 0.073 were psychiatrists, 0.196 psychiatric nurses, 0.007 psychologists, 0.002 social workers, 0.003 occupational therapists and 0.029 other health workers (including auxiliary staff, non-doctor healthcare workers, medical assistants, and professional and paraprofessional psychosocial counsellors) per 100000 population. ${ }^{4}$ Although the number of mental health professionals has increased since then, the population has proliferated even faster. The budget allocated for the mental health sector is only 0.44 percent of the total budget. ${ }^{4}$ There is only one national institute, the National Institute of Mental Health (NIMH) in Dhaka, with postgraduate training, 200 in-patient beds and an outpatient service. There is one mental hospital in Pabna (the northern part of Bangladesh) with 500 beds. ${ }^{2}$ There are 50 out-patient mental health facilities, 31 community-based psychiatric in-patient units and 11 community residential facilities. There are no facilities for follow-up care in the community and no day treatment mental health facilities in the entire country. ${ }^{4}$

The country is struggling with repeated disasters, which have been demonstrated to negatively affect mental health. Considering the limited resources and shortage of human capital needed to efficiently respond to continuous stressors and disasters, current national capacity is limited. The aim of the current report is the assessment of the situation of stress-related mental health services in the country in order to assist in proper initiatives to improve mental health and preparedness for future anticipated stressful situations.

Pertinent data were collected from the Ministry of Health and the Dhaka NIMH by electronic searches of their databases supplemented by manual searches.

\section{Major natural and man-inflicted disasters}

According to a government report, ${ }^{5}$ in a sample of 10 years (1988-1998), fatal natural acute disasters occurred almost annually. This included multiple, consistently almost annual, floods that from 1988 to 1998 cost over 1000 lives. Fatalities from cyclones in 1988, 1991 and 1997 were 5704, 138868 and 550, respectively. In 1989, 800 people died from drought, and a 1996 tornado caused 545 deaths. Tsunami is considered to be a new threat. In a recent one there were several fatalities.

Poverty and population congestion contribute to building collapses, fires, and road and river traffic accidents. ${ }^{5}$ Violence at various levels is almost a daily occurrence.

The independence war of Bangladesh in 1971 left many people dead, injured, homeless and mentally traumatised. It is of note that more than half of the injured freedom fighters $(51.6 \%)$ had subsequent mental disorders; $31.3 \%$ of them developed post-traumatic stress disorder (PTSD) and $76.77 \%$ were diagnosed with major depressive disorder (MDD). ${ }^{6}$

A UNICEF-supported survey of victims of a violent tornado in Bangladesh in 1996 revealed that $66.6 \%$ were 'psychologically traumatised' and required emergency psychological services. ${ }^{7}$ On average, women were more psychologically affected than men. Eighty per cent of the victims below 12 years old also needed such services.

The prevalence of mental disorders among child and adolescent victims following the 2007 Bangladesh cyclone Sidr was $48.1 \%$. Common mental disorders included separation anxiety disorder, specific phobias, social phobia, panic attacks or agoraphobia, PTSD and MDD. ${ }^{8}$ Psychosocial support was provided to the cyclone victims by the Dhaka NIMH and the Bangladesh Association of Psychiatrists in collaboration with the WHO and other non-governmental organisations.

An NIMH WHO-supported study of the victims of the collapse of a nine-storey building in 2013 found that 26\% were suffering from PTSD, $12 \%$ from acute stress disorder, $11 \%$ from sleep disorders and $4 \%$ from panic attacks. ${ }^{9}$ Psychological first aid (PFA) was provided to the affected individuals with the support of the WHO, following the standard international field operation guide for PFA. The principal components included contact and engagement, safety and comfort, stabilisation, information-gathering, current needs and concerns, practical assistance, connection with social support, information on coping and linkage with collaborative services. Hypnotics and anxiolytics (e.g. clonazepam, diazepam, propranolol and sertraline) were also given for a short time.

\section{Mental health of refugees}

Since 2017, Bangladesh has absorbed 915000 refugees from neighbouring Myanmar; most of them are Muslim Rohingya. An assessment of the refugees from Myanmar by the UN High Commissioner of Refugees indicated that many of them were experiencing acute stress reactions, grief reactions, adaptive stress reactions, posttraumatic stress symptoms, and feelings of rejection and sadness. ${ }^{10}$ Mental health was integrated within basic health services for the refugees from Myanmar according to the WHO Mental Health Gap Action Programme (mhGAP) guidelines, particularly the humanitarian version. Primary healthcare (PHC) providers have been trained with mhGAP methods. Cases of severe mental disorders are referred to nearby district hospitals, which were recently enhanced with psychiatrists and psychologists. The vulnerable refugee population adds to the strain on the professional services that especially in rural areas are limited. This causes resentment among the local residents, who perceive the refugees as competitors for limited economical and public services resources. 


\section{Bangladeshi immigrants abroad and their effects on the native country}

Unemployment and under-employment have caused extensive migration of labourers to other countries, mostly to the Middle East. ${ }^{2}$ However, Bangladeshis have migrated to the USA and the UK since the 1950 s and constitute significant minority communities there.

Most of the Bangladeshi immigrants living abroad leave their families behind in the native land. Frequently, they send some of their earnings back home, thus contributing to the local economy. However, their detachment from their families result in difficulties for them as well as for their families. Immigrant labourers frequently visit Bangladesh for short periods, and some seek mental health interventions during their visits. Often, families suffer acute stress reactions upon their departure. The magnitude and severity of these stressors is still awaiting a systematic investigation, but the additional workload on local health services is apparent.

Bangladeshi immigrants to the UK were a focus of a study of patients of King's Cross and Regent's Park community mental health team in 2001. The main diagnoses were schizophrenia $(51.8 \%)$, depression $(22.2 \%)$ and bipolar affective disorder $(7.4 \%) .{ }^{11}$ Somatisation is a major issue among people of Asian communities. Common socioeconomic factors contributing to psychiatric morbidity among immigrants in Britain include low income, unemployment, housing problems, language difficulties, isolation, and family stress including strained relationships with children, as well as gender issues. Women complained of high stress due to a lack of integration with society and experiencing racism. ${ }^{11}$

The mental health of Bangladeshi transient migrants in the Persian Gulf countries is of concern. There have been media reports that at times of population needs, these migrants did not receive the same support as citizens. Most are single men and women who may need mental rehabilitation upon their return home, a fact that causes an additional strain on public health, which the government is attempting to solve.

\section{Recent developments}

The approach of responding to needs only after the occurrence of a disaster or crisis has been replaced in Bangladesh by the concept of total disaster management involving prevention and mitigation, preparedness, response, recovery and development. The government of Bangladesh has expressed total commitment to reduction of the human, economic and environmental costs of disasters by enhancing the overall disaster management capacity. Post-disaster mental health is included in this programme. The government has established one-stop crisis centres at various hospitals and locations in the country, with a proper referral system for victims of abuse. They have also made special arrangements for taking care of female workers returning from abroad with a history of abuse and exploitation.

Several mental disorders have been included in the government's definitions of disabilities followed by allocation of funding. The Mental Health Act, Bangladesh, 2018, contributes to the development of mental health services, including disaster- and stress-related mental health. ${ }^{12}$ The goal of the government is to integrate mental health services in PHC and thus provide culturally sensitive cost-effective services even during periods of crisis. No Essential Service Package of the government's health sector is specified for people with mental illnesses. The government's safety net programme covers a portion of individuals with neurodevelopmental disorders and some patients with chronic mental illness such as schizophrenia, but support to persons with mental illness living at home is still in planning.

The Ministry of Relief and Disaster has developed its own policy and programme for disaster management, including a mental health policy and strategic planning in anticipation of, during and following a disaster.

\section{Need to improve capacity of mental health providers and services}

The Bangladeshi government shows sensitivity towards people's physical and mental health needs. Several mental disorders have been included in government definitions of disabilities, with budgeting and funding ramifications. However, for productive progress there is a need for adequate resources, enhanced human capital and recognition of the importance of a comprehensive integration of all aspects of wellbeing, as well as establishment of functioning partnerships for well-being. ${ }^{13}$ As is the case in many countries, Bangladesh does not have enough psychiatrists to fulfil its needs. Young medical graduates need incentives to take psychiatric residencies, and primary care providers need to be proficient in recognising mental symptoms and giving basic treatment. There is also a challenge in involving traditional healers, 'village doctors', nurses and other healthcare providers in the management of mental well-being issues. Interdisciplinary teams for well-being should be evolved to improve healthcare capacity. Their implementation requires outside assistance and budgeting. This assistance has been partially available during crises and should be activated for preventive and routine operations.

\section{Conclusion}

Assessment of stressors and mental health issues in Bangladesh illuminates gaps in knowledge and services in stress-related mental health. Some progress has been achieved by replacing the approach of responding to mental health needs only after the occurrence of a crisis by a concept of total management through a PHC approach. Further development of infrastructure, improving logistics, and enhancing workforce 
support and training have been planned. Multidisciplinary teams for planning and implementation of services, as well as collaboration with other related sectors of government, are essential elements for success. Owing to current deficient resources, support from national and international agencies is needed.

\section{Funding}

None.

\section{Author contributions}

All co-authors contributed to ideas and data. The article was initiated by U.H. who outlined and finalized it. R.H. pursued the work under close supervision of the local co-authors. The group is currently working on the ramifications of this article.

\section{Declaration of interest}

ICMJE forms are in the supplementary material, available online at https://doi.org/10.1192/bji.2020.57.

\section{References}

1 Rabbani G, Ahmed H, Desai G, Bhugra D. The Bangladesh perspective. In: Routledge Handbook of Psychiatry in Asia (ed D Bhugra). Routledge, 2015.

2 Central Intelligence Agency, USA. The World Factbook. 2020.

3 Economy of Bangladesh. Economy of Bangladesh. 2020 (https://en.wikipedia.org/wiki/Economy_of_Bangladesh).

4 World Health Organization, Ministry of Health \& Family Welfare. WHO-AIMS Report on Mental Health System in Bangladesh. 2007.
5 Choudhury W, Quraishi F, Haque Z. Mental health and psychosocial aspects of disaster preparedness in Bangladesh. Int Rev Psychiatry 2006; 18(6): 529-35.

6 Mohit MA, Sobhan MA, Ahmed HU. Post-traumatic stress disorder among war-injured freedom fighters of Bangladesh. Bangladesh J Psychiatry 2006; 20(2): 2-36.

7 Social Assistance and Rehabilitation for the Physically Vulnerable (SARPV-Bangladesh). Psychological Effects of Natural Disaster on Human Being of Gopalpur at Tangile. An Empirical Evidence on Tangile Tornado of 13th May 1996 Based on an Enquiry after Four and Half (4.5) Months. 1996.

8 Mullick M, Nahar ], Chowdhury N, Rahman W, Islam M, Qusar M, et al. Psychiatric disorders among the children of 5 to 18 years old of 'SIDR' affected areas. Bangabandhu Sheikh Mujib Med Univ J 2016; 7(1): 20-6.

9 World Health Organization South-East Asia. Searo.who.int WHO, 2020 (http://www.searo.who.int/bangladesh/topics/ psychosocial/en/).

10 UN High Commissioner of Refugees. Findings from Community Assessments Conducted with Women, Men, Boys and Girls of Different Ages and Diverse Backgrounds living in Kutupalong, Nayapara and Kerontoli/Chakmarkul. UNHCR, 2017.

11 Bisby N, Singam S, Beattie A, Ekiko F, Clilverd A. The Mental Health Needs of the Bangladeshi Community in Camden: An Action Research Project. Bengali Womens Health Project, Camden Primary Care Trust NHS, Camden and Islington Mental Health and Social Care Trust NHS, 2003.

12 Bangladesh Government. Mental Health Act. 2018, 14943-57.

13 Halbreich U, Schulze T, Botbol M, Javed A, Kallivayalil R, Ghuloum S, et al. Partnerships for interdisciplinary collaborative global well-being. Asia Pac Psychiatry 2019; 11(2): e12366.

\title{
MENTAL HEALTH LAW PROFILE \\ Crime and punishment: Pakistan's legal failure to account for mental illness
}

\author{
Romesa Qaiser Khan ${ }^{1}$ and Abdul Moiz Khan ${ }^{2}$ [
}

${ }^{1}$ MBBS, King Edward Medical University, Lahore, Pakistan ${ }^{2}$ Second Year Internal Medicine Resident, Albany Medical Center, New York, USA

Email: abdulmoiz92@gmail.com

Keywords. Suicide; transcultural psychiatry; psychiatry and law; low and middle income countries; human rights.

First received 26 Jul 2019 Final revision 11 Dec 2019 Accepted 28 May 2020

doi:10.1192/bji.2020.30

(C) The Authors 2020. This is an Open Access article, distributed under the terms of the Creative Commons Attribution licence (http://creativecommons.org/ licenses/by/4.0/), which permits unrestricted re-use, distribution,
The Mental Health Ordinance 2001 was the last comprehensive legislation on mental health policy in Pakistan, replacing the Lunacy Act 1912. Since then, most of the amendments to the act have only delineated the jurisdiction of the provincial governments. Failure to account for mental illness in Pakistan brings with it unique challenges, such as the criminalisation of suicide and exploitation of blasphemy laws. There is a need for organised efforts to promote awareness of mental illness, amend the obsolete legislation in conformity with the scientific evidence, implement mental health policy effectively and deal with sensitive issues that have a strong sociocultural or religious background.

\section{The evolving crisis in Pakistani mental healthcare}

The Pakistani healthcare system is no stranger to challenges. A dearth of infrastructure, constant cuts to a meagre health budget, overpopulated hospitals and overwhelmed physicians - by and large, the system in its entirety is either a marvel of medicine based on sheer human effort or a pariah exemplifying poor policy-making on the part of unconcerned politicians. Yet even in these less than ideal circumstances, there is a proverbial black sheep in the fields of medical care - mental illness is still a concept at best foreign to most and at worst challenged for its very existence.

To provide a brief insight, the World Health Organization's Mental Health Atlas Project gathers country-specific data in order to analyse 